\title{
IV CONGRESO INTERNACIONAL SOBRE INVESTIGACIÓN EN LA DIDÁCTICA DE LAS CIENCIAS Y DE LAS MATEMÁTICAS
}

\author{
Barcelona, 13 a 16 de septiembre de 1993
}

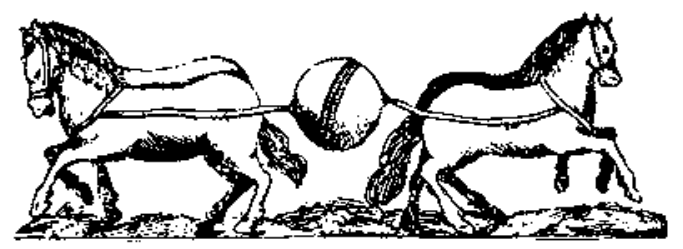

\section{DIEZ AN̄OS DE ENSEÑANZA DE LAS CIENCIAS}

\begin{abstract}
Presentación
El IV Congreso se celebra cuando la Revista acaba de cumplir su primera década y cuando hemos entrado ya en la última de nuestro siglo. Éste es un hecho que invita a la reflexion $y$ al balance $y$ ante el cual el Congreso no ha de permanecer indiferente. Porque diez años es un periodo suficientemente amplio para hacer balance de un proyecto, porque durante los últimos diez años el sistema educativo de nuestro país ha sido renovado, porque es preciso profundizar en la evolucion científica general para sustentar con rigor el futuro de nuestra investigación, porque vivimos en un mundo cada vez más interdependiente que se vuelve hacia la ciencia buscando tanto respuestas como coartadas.
\end{abstract}

Es necesario profundizar y ampliar el diálogo entre las ciencias naturales y las ciencias humanas. La ciencia forma parte integrante de la cultura y de la sociedad de una época; por eso, el discurso científico que no reconozca la adscripcion al mundo en el que vive y pretende describir y se mantenga en una exterioridad ensimismada o disociada, podrá resultar más o menos arrogante, pero estará cada vez más vacío de sentido.

Esperamos que el IV Congreso sea el marco adecuado que facilite el intercambio de experiencias entre los investigadores y proporcione también elementos de reflexión para el conjunto del profesorado.

\section{Modelo organizativo}

De acuerdo con las consideraciones apuntadas en la presentación se han previsto las stguientes modalidades de actuaciones:
A) Sesiones plenarias sobre temas de interés general.

1. Exposición de ponencias que ofrezcan una visión panorámica de lo que ha sido la investigación en la didáctica de las ciencias en los últimos años, revisen el cuerpo teórico elaborado y reflexionen acerca de algunas líneas de futuro.

2. Exposición de ponencias que revisen algunos de los temas abordados por la ciencia en la actualidad cuyo impacto social implique la revisión profunda de enfoques y contenidos de las ciencias en los distintos niveles educativos. (Por ejemplo, ponencias sobre temas como "Ciencia, desarrollo tecnológico y cambio social", "Ciencia y género", "Enseñanza de las ciencias y Reforma educativa"...).

B) Sesiones simultáneas sobre temas de interés específico

1. Presentación y debate de ponencias y comunicaciones que pormenoricen algunos aspectos de los temas mencionados en el apartado anterior.

2. Presentación y debate de comunica. ciones sobre trabajos inéditos de investigación didáctica.

C) Exposición de pósters.

\section{Inscripción}

La preinscripción deberá realizarse antes del 15 de febrero de 1993, enviando el boletín adjunto en el que consten todos los datos solicitados.

Por razones de capacidad de locales y de exigencias organizativas el numeto de plazas será limitado. En caso de ser denegada la preinscripción se comunicará antes del 20 de abril.

La inscripción definitiva habrá de realizarse antes del 30 de mayo de 1993 mediante el pago de los derechos de inscripción. El importe previsto es de 22.000 ptas. (19.000 ptas. para los suscriptores de Enseñanza de las Ciencias).

Envio y aceptación de comunicaciones y pósters

Quienes deseen presentar una comunicación o un póster habrán de enviar, junto al boletín de preinscripción, un resumen de la misma (original y dos copias) y el disquet -preferentemente de $31 / 2$ "- en uno de los siguientes procesadores de textos:

Programas de PC: Word Star, Word Perfect, Page Maker o MS Word. Macintosh: todos.

El resumen de la comunicación o del póster deberá reunir las siguientes características:

Extensión máxima de 8.500 caracteres (aproximadamente tres hojas de tamaño DIN-A4 en letra de ordenador en cuerpo máximo de 11 puntos). Título escrito en mayúsculas. Autor/es, primer apellido e inicial del nombre todo en mayúsculas. Lugar y dirección de trabajo. Persona encargada de la presentación de la comunicación en el congreso y autores/as que piensan asistir al congreso.

Para facilitar la edición de las comunicaciones se recomienda seguir las siguientes normas tipográficas: 
- no hacer entrada en primera línea del texto, ni sangrías,

- no hacer retorno al final de las líneas, - entre uno y otro párrafo dar, solamente, un retorno.

Antes del 20 de abril, el comité de seiec. ción comunicará a los autores la aceptación o no de los trabajos remitidos.
Los resúmenes de las comunicaciones seleccionadas para la presentación oral y la relación de títulos y autores de las comunicaciones aceptadas para la presentación póster serán editados en una publicación que se enviará a los congresistas durante el mes de jutio para facilitar su participación en las diferentes sesiones.

\section{Infraestructura y alojamiento}

Está previsto desarrollar el congreso en el campus de la UAB en Bellaterra. Se facilitará información sobre alojamiento, parte del cual podrá efectuarse en el mismo campus.

\section{BOLETÍN DE PREINSCRIPCIÓN AL CUARTO CONGRESO INTERNACIONAL DE INVESTIGACIÓN DIDÁCTICA ORGANIZADO POR ENSEÑANZA DE LAS CIENCIAS}

Rellenar con tinta negra para facilitar las fotocopias y remitir a:

Enseñanza de las Ciencias / ICE Universitat Autonoma de Barcelona / 08193 Bellaterra (Barcelona)

\section{Datos personales}

Nombre y apellidos

Calie o plaza

Código postal

Población. Teléfono

\section{Datos profesionales y curriculares}

Titulacion

Puesto de trabajo (describir brevemente)

Dirección

¿Forma parte de algún grupo de trabajo?

Sí [ ] No [ 1

En caso afirmativo indicar nombre, institución a la que está asociado y principales líneas de trabajo:

¿Ha publicado previamente trabajos de investigación y/o innovación didáctica?

Sí $\square \quad$ No $\square$

En caso afírmativo adjuntar una selección de títulos recientes, utilizando el formato habitual de las referencias en Enseñanza de las Ciencias.

\section{Propuestas de comunicación y/o póster}

¿Hace alguna propuesta de comunicación? ¿Hace alguna propuesta de póster?

$$
\begin{array}{ll}
\text { Sí } & \text { No } \square \\
\text { Sí } \square & \text { No }
\end{array}
$$

En caso afïmativo adjuntar resúmenes confeccionados en la forma descrita más arriba e indicar, en su caso, quiênes de los coautores se inscriben también al Congreso. 